\title{
Avaliação das práticas de fracionamento de produtos de origem animal em supermercados em Porto Alegre ${ }^{1}$
}

\author{
Evaluation of practices adopted for slicing of animal-derived foods in supermarkets of Porto Alegre, \\ Brazil \\ Carina Philomena Thebich Gottardi², Vanessa D. Mottin², Lisandra Mürmann², Cláudia Ache \\ Saldanha ${ }^{3}$,Verônica Schmidt ${ }^{4} \&$ Marisa Cardoso ${ }^{4}$
}

\begin{abstract}
RESUMO
Os setores de fiambreria dos supermercados e hipermercados fracionam quantidades de alimento em escala próxima à industrial, estando submetidos a elevado risco de manipulação e contaminação cruzada. A partir disso, o objetivo desse estudo foi avaliar as práticas adotadas para manipular produtos fracionados de origem animal. Foi conduzido um estudo observacional onde foram aplicados questionários em 37 supermercados de Porto Alegre. A maioria dos estabelecimentos contava com responsável técnico $(78,4 \%)$, treinava $(67,6 \%)$ e supervisionava $(78,4 \%)$ os manipuladores e não tinha Manual de Boas Práticas de Fabricação (83,3\%). Quanto aos procedimentos de higienização, 62,2\% utilizavam protocolo de higienização que consistia em uso de detergente com posterior aplicação de sanificante para equipamentos e mesas de manipulação e 70,3\% utilizavam produto específico para higienização das mãos dos manipuladores. As concentrações e frequiências adotadas para esses procedimentos eram geralmente desconhecidas. A partir disso, conclui-se que procedimentos de treinamento, controle e avaliação devem ser implementados para garantir a segurança dos alimentos manipulados nesses estabelecimentos.
\end{abstract}

Descritores: Supermercado, Produtos de Origem Animal, Manipulação, Condições Higiênico-Sanitárias.

\begin{abstract}
Retail establishments, like supermarkets, process animal-derived foods in a scale almost as high as food factories. Thus, products processed in these establishments are exposed to the same recontamination risk as in the industrial environment. The aim of this study was to verify the environmental contamination level in supermarket areas, where animal-derived products are sliced and packed. An observational study was conducted in 37 supermarkets located in Porto Alegre (Brazil). Most establishments had a supervisor (78.4\%), had training activities for the employees $(67.6 \%)$ and supervising the manipulation activities (78.4\%). Most (83.3\%) supermarkets did not have a Good Manufacture Practice Manual. Regarding the sanitization in processing areas, $62.2 \%$ had a cleaning and disinfection protocol based on the application of a liquid detergent followed by a disinfectant, and $70 \%$ adopted a commercial product for hand antisepsis. However, the concentration of the disinfectant and the frequency of their application were not known by the employees. It was concluded that a better monitoring of sanitization procedures in these areas have to be adopted to guarantee the safety of processed food.
\end{abstract}

Keywords: Supermarkets, Animal-derived Products, Manipulation, Hygienic-sanitary Conditions.

${ }^{1}$ Trabalho originado de Dissertação de Mestrado do primeiro autor. ${ }^{2}$ Programa de Pós-Graduação em Ciências Veterinárias, Faculdade de Veterinária, Universidade Federal do Rio Grande do Sul (UFRGS), Porto Alegre/RS, Brasil. ${ }^{3}$ Equipe de Vigilância em Alimentos, Secretaria Municipal de Saúde, Porto Alegre/RS, Brasil. ${ }^{4}$ Departamento de Medicina Veterinária Preventiva, Faculdade de Veterinária, UFRGS. CORRESPONDÊNCIA: M. Cardoso [mcardoso@ufrgs.br; Fax: (55) 51+ 3308 7305]. 


\section{INTRODUÇÃO}

Alimento seguro é definido como aquele em que constituintes ou contaminantes que causem mal à saúde do consumidor estão ausentes ou abaixo do limite de risco [7].

O Manual de Boas Práticas de Fabricação (BPF) é um documento que descreve as operações realizadas pelo estabelecimento, incluindo a manutenção e higienização das instalações, dos equipamentos e dos utensílios, o controle da higiene e saúde dos manipuladores, entre outros aspectos para a garantia de qualidade do alimento preparado. O Manual de BPF passou a ser exigido pela Resolução RDC $\mathrm{n}^{\circ}$ 216 de 15 de setembro de 2004, e aplica-se a todos os serviços de alimentação, incluindo supermercados e congêneres [5].

O setor supermercadista brasileiro tem apresentado constante expansão, sendo responsável por parcela considerável do mercado de varejo de alimentos. Os supermercados convencionais são estabelecimentos de porte médio caracterizados pelo comércio de alimentos, ofertando uma média de 10.000 ítens ao consumidor [11]. Nos últimos anos, observou-se o surgimento de lojas maiores denominadas hipermercados, onde uma média de 60.000 ítens é oferecida, abrangendo alimentos e produtos têxteis e eletrônicos [9]. Nesses estabelecimentos, o movimento de vendas implica no fracionamento de grande quantidade de produtos, notadamente aqueles de origem animal. Esses produtos, recebidos da indústria onde haviam sido processados sob condições controladas, são submetidos a novo risco de manipulação e contaminação cruzada no setor de fracionamento. Apesar disso, as condições higiênicas dos ambientes de fracionamento de produtos de fiambreria de supermercados é pouco estudada. Com isso, o objetivo do estudo foi avaliar as condições relacionadas às práticas de manipulação e higienização desses setores em supermercados do município de Porto Alegre.

\section{MATERIAIS E MÉTODOS}

Foi conduzido um estudo observacional, no qual foram aplicados questionários em 37 lojas pertencentes a redes de supermercados e hipermercados considerados representativos em Porto Alegre. O questionário visou à obtenção de informações sobre as práticas de limpeza e higiene da área de manipulação de fiambres e procedimentos de fracionamento, tendo sido aplicado em todas as lojas classificadas como hipermercado ou supermercado convencional de acordo com critérios de Parente [11] e Lukianocenko [9]. As visitas foram realizadas em conjunto com a Equipe de Vigilância de Alimentos da Secretaria Municipal da Saúde de Porto Alegre. O questionário foi conduzido sempre pelo mesmo entrevistador, sendo aplicado preferencialmente ao encarregado do setor de fracionamento. Foram incluídas perguntas gerais a respeito do estabelecimento, tais como: número de clientes/dia, volume de produtos fatiados/ dia e perguntas específicas a respeito dos protocolos de lavagem e manipulação das áreas de fatiamento. Também foi questionada a existência de responsável técnico e Manual de Boas Práticas de Fabricação. Paralelamente, o estado de conservação das mesas de manipulação, material adequado da mesa, piso e paredes, presença de sabão líquido e papel toalha foram observadas e anotadas pelo entrevistador.

\section{RESULTADOS}

Dos 37 estabelecimentos visitados, somente em um não houve a concordância em responder ao questionário. Neste estabelecimento, foram considerados apenas os ítens que envolviam a observação feita pelo entrevistador.

Dois estabelecimentos eram centrais de fatiamento, isto é, os produtos eram fracionados e posteriormente distribuídos para várias lojas da rede. Mais da metade dos estabelecimentos que foram entrevistados $(59,5 \%)$ recebia entre 1001 e 3000 clientes/ dia, sendo que nos cinco hipermercados eram atendidas mais de 6000 pessoas diariamente (Figura 1A). Quanto à quantidade de produtos fatiados por dia, a maioria dos estabelecimentos processava entre $50 \mathrm{e}$ $500 \mathrm{~kg}$ de produtos, apenas uma central de fatiamento e dois hipermercados processavam quantidades superiores (Figura 1B). Os produtos mais freqüentemente fatiados nos estabelecimentos eram queijo, presunto e outros embutidos cárnicos, que não sofrem qualquer tipo de processamento térmico posterior, sendo destinados ao pronto consumo.

Em 11 estabelecimentos $(29,7 \%)$ foi informado que havia área exclusiva para a atividade de fracionamento. No entanto, encontraram-se indícios de que a maioria das lojas realizava outras atividades nessa área, como o preparo de sanduíches, pizzas e outros lanches. Durante as entrevistas, pode-se constatar a presença de diversos alimentos como vegetais, pães, molhos e outros ingredientes nestas áreas. 
Figura 1. Distribuição dos estabelecimentos onde foram aplicados os questionários, de acordo com o número de clientes atendidos por dia (A) e de acordo com a quantidade $(\mathrm{kg})$ de produtos fracionados por dia (B).

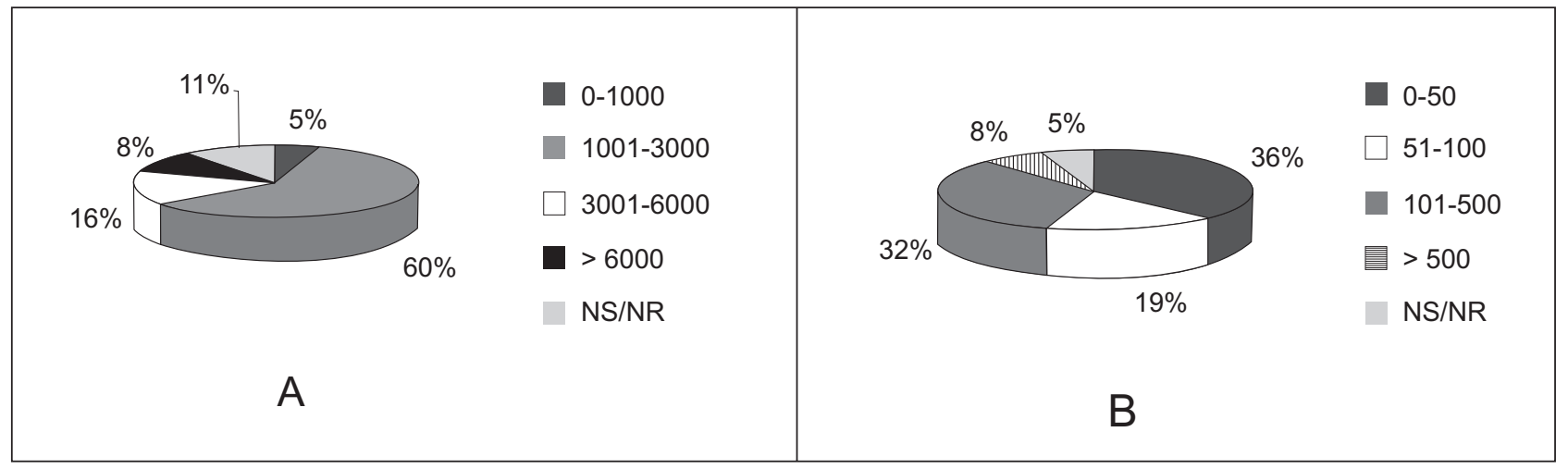

A maioria $(78,4 \%)$ das salas de fracionamento eram climatizadas e $62,2 \%$ informaram registrar as temperaturas aferidas em planilhas, no entanto, somente 43,2\% apresentavam termômetro em local visível. Em dez estabelecimentos, onde houve a aferição da temperatura ambiente, observou-se variação entre $11^{\circ} \mathrm{C}$ e $22^{\circ} \mathrm{C}$, com média de $15,46^{\circ} \mathrm{C}$.

A maioria das lojas $(78,4 \%)$ contava com responsável Técnico (RT), cumprindo o que está previsto na Portaria n $1428 / M S$ de 1993 para estabelecimentos relacionados à área de alimentos [4]. Entretanto, $83,8 \%$ não contavam ainda com manual de BPF como previsto na legislação [5].

Nos 25 estabelecimentos que realizam algum tipo de treinamento para manipuladores, foram citados: curso na própria empresa ministrado pelo Responsável Técnico (RT), cursos em empresas fornecedoras, além da palestra ministrada pela Equipe de Vigilância de Alimentos da Secretaria Municipal da Saúde. No entanto, onze lojas $(29,7 \%)$ ainda não ofereciam treinamento a seus funcionários. A maioria das lojas $(78,4 \%)$ informou que havia supervisão dos manipuladores para o cumprimento das normas de higiene, ausência de uso de adornos e esmalte, integridade da pele e estado de saúde. Na maioria das lojas visitadas $(78,4 \%)$ os manipuladores não utilizavam luvas para o processamento dos alimentos.

Em 70,3\% dos estabelecimentos constatouse a presença de pessoas estranhas à atividade de fracionamento no local onde ocorria essa operação. Entre as pessoas estranhas, os promotores, isto é, funcionários das empresas fornecedoras de produtos de fiambreria também circulavam nestas áreas.

A maioria das lojas $(97,3 \%)$ contava com mesas de manipulação com material adequado, isto é, liso, lavável, impermeável, resistente, de fácil higienização e não contaminante, estando em conformidade com a Resolução 275/02 [2].

Dos estabelecimentos visitados, 59,5\% tinham fatiadora de produtos de fiambreria com uso específico para queijos ou para produtos cárnicos. As lojas que utilizavam o mesmo equipamento para fracionar diferentes produtos informaram que processavam primeiro os queijos e realizavam higienização antes de fracionar os cárnicos. No entanto, não higienizavam a fatiadora entre diferentes produtos cárnicos, pois consideravam não haver necessidade, uma vez que os ingredientes eram os mesmos.

As informações obtidas pelo questionário demonstraram que, para a higienização de equipamentos e mesas de manipulação, a maioria dos estabelecimentos $(62,2 \%)$ utilizava detergente com posterior aplicação de um sanificante, geralmente a base de hipoclorito de sódio (Tabela 1). O responsável pela higienização era o manipulador que estava encarregado de realizar os procedimentos previstos no protocolo imediatamente após o uso do equipamento. No entanto, quando questionadas sobre a frequiência da realização dos procedimentos, a grande parte dos entrevistados não soube informar, relatando que a higienização era feita no final do turno e sempre que necessário, indicando que não havia uma padronização nesse procedimento.

Para higienização das mãos dos manipuladores, $70,3 \%$ dos estabelecimentos utilizava produto específico para este fim, indicado por uma empresa fornecedora de produtos de limpeza, a base de 2,4,4'tricloro-2'-hidroxidifenil. Quanto à freqüência de higienização das mãos, verificou-se que semelhante ao caso dos equipamentos, não havia padronização. 
Tabela 1. Tipos de protocolos de higienização adotados para ambiente e manipuladores de alimentos adotados em 37 supermercados e hipermercados de Porto Alegre.

\begin{tabular}{|l|c|c|}
\hline \multicolumn{1}{|c|}{ Protocolo } & Equipamentos/Mesas (\%) & Mãos (\%) \\
\hline Detergente & 13,5 & 24,3 \\
\hline Detergente e sanificante & 62,2 & 0 \\
\hline Detergente e vinagre & 2,7 & 0 \\
\hline Detergente e álcool & 18,9 & 2,7 \\
\hline Produto específico* & 0 & 70,3 \\
\hline NR/NS** & 2,7 & 2,7 \\
\hline Total & 100 & 100 \\
\hline
\end{tabular}

* Produto comercial a base de 2,4,4'-tricloro-2'-hidroxidifenil.

** NS/NR: não sabe ou não respondeu

A respeito da concentração dos produtos utilizados, a maioria dos entrevistados relatou que utilizava aquela recomendada pelo fabricante. No entanto, foi verificado que as respostas dadas nessa etapa não correspondiam aos procedimentos realmente adotados na rotina. Em duas lojas amostradas, os produtos citados no questionário não estavam presentes no setor de fracionamento, estando em seu lugar detergente neutro comum. Em outra loja, que relatou na entrevista que usava o protocolo detergente com posterior aplicação de sanificante, observou-se o uso exclusivo de álcool em concentração desconhecida. Nesse sentido, observou-se que a maioria dos estabelecimentos não seguia uma concentração previamente definida dos produtos utilizados.

\section{DISCUSSÃO}

As entrevistas conduzidas no presente estudo demonstram a parcela importante da população atendida pelos estabelecimentos visitados, bem como o volume de alimentos manipulados. Isto enfatiza a importância desse tipo de estabelecimento comercial para a garantia da segurança dos alimentos consumidos pela população e a abrangência potencial de contaminações que venham a ocorrer em produtos por eles manipulados.

A quantidade de produtos fracionados, acima de $100 \mathrm{Kg}$ diariamente na maioria dos estabelecimentos, é comparável ao volume processado em escala industrial. Entretanto, ao contrário das indústrias sob inspeção federal, não existem Procedimentos Operacionais Padrão (POP), Procedimento-padrão de Higiene Operacional (PPHO) ou programas de Análises de Perigos e Pontos Críticos de Controle (APPCC) estabelecidos.
Os resultados obtidos demonstram que a maioria dos estabelecimentos visitados respeitava os ítens previstos em regulamentações existentes para a comercialização de alimentos. Nesse sentido, a maioria das lojas contava com Responsável Técnico, realizava algum tipo de treinamento para os funcionários, supervisionava os manipuladores quanto às normas de higiene e estado de saúde e tinha estrutura de ambiente e superfície de manipulação de alimentos de acordo com a legislação vigente $[2,4,13]$.

Apenas a existência de Manual de BPF, também exigido pela legislação [5], não era cumprida pela maioria dos estabelecimentos. Entretanto a realização dos questionários coincidiu com o período previsto para o início da vigência da lei e, por isso, estava em fase de implementação na maioria dos estabelecimentos. Segundo a legislação vigente, os serviços de alimentação devem dispor do Manual de BPF, o qual deve estar acessível aos funcionários envolvidos e disponível às autoridades sanitárias, quando requerido.

Na prática, o Manual de BPF é o documento que descreve todas as ações previstas em programa de Boas Práticas de Fabricação, o qual deve estar implantado no estabelecimento que fabrica ou comercializa alimentos. As normas que estabelecem as chamadas BPF, por sua vez, envolvem requisitos fundamentais, inclusive regras de higiene pessoal e de limpeza do local de trabalho [10]. Justamente nesses aspectos, observa-se que houve a concentração das falhas observadas no presente estudo.

A evidente ausência de padronização no que diz respeito aos procedimentos adotados para o fracionamento dos alimentos, bem como a existência, no ambiente de manipulação, de pessoas e pro- 
dutos estranhos ou a inexistência de um cronograma na utilização de equipamentos de fracionamento, podem favorecer a contaminação cruzada de alimentos $[3,14]$. Além disso, podem propiciar a transferência de agentes causadores de Doenças Transmitidas por Alimentos (DTA) que podem estar aderidos às superfícies comumente encontradas em plantas de processamento de alimentos, formando biofilmes [8].

Os aspectos relacionados à higienização de equipamentos e manipuladores também demonstrou estar aquém do requerido para garantir um alimento seguro. Apesar de a maioria dos estabelecimentos adotarem o uso de detergente associado ao sanificante à base de hipoclorito de sódio, como é largamente utilizado na indústria de alimentos [1], a concentração adotada e a frequiência de utilização eram desconhecidas pelos operadores. Quanto à higienização das mãos, a mesma situação foi constatada, indicando que a transferência de patógenos por manipuladores poderia ocorrer. Esse é um aspecto relevante, pois a ausência de lavagem das mãos ou higienização deficiente são apon- tadas como causas da transferência de patógenos para alimentos manipulados [12], tornando esse procedimento de fundamental importância nos estabelecimentos que processam alimentos [6].

A elaboração do Manual de BPFs certamente poderá contribuir para a correção dos aspectos deficientes que foram constatados, entretanto, é preciso que o mesmo seja resultado de um programa de BPF implantado. Caso contrário será apenas um documento desconhecido e pouco utilizado pelos manipuladores de alimentos. Para tanto, gerências, chefias e supervisão devem estar engajadas para que ocorra o êxito do programa, bem como as ações para motivação e treinamento de funcionários precisam ser estabelecidos [10].

Em conclusão, os resultados obtidos demonstram a importância da fiscalização e orientação realizadas nesses estabelecimentos, uma vez que a população potencialmente exposta a um possível agente causador de DTA veiculado por produtos manipulados nesses locais é extremamente elevada.

\section{REFERÊNCIAS}

1 Andrade N.J. \& Macêdo J.A. 1996. Higienização na Indústria de Alimentos. São Paulo: Varela, 182p.

2 ANVISA - Agência Nacional de Vigilância Sanitária. 2002. Análise de Perigos e Pontos Críticos de Controle-APPCC. Disponível em: <http://www.anvisa.gov.br/alimentos/appcc.htm>. Acessado em 10/2005.

3 Banatvala N., Magnano A.R., Cartter M.L., Barrett T.J., Bibb W.F., Vasile L.L., Mshar P., Lambert-Fair M.A., Green J.H., Bean N.H. \& Tauxe R.V. 1996. Meat grinders and molecular epidemiology: two supermarket outbreaks of Escherichia coli O157:H7 infection. The Journal of Infectious Diseases. 173: 480-483.

4 Brasil. 1993. Ministério da Saúde. Agência Nacional de Vigilância Sanitária. Portaria no 1428/MS, de 26 de novembro de 1993. Disponível em: <http://www.anvisa.gov.br/legis/portarias/1428 93.htm>. Acessado em 11/2003.

5 Brasil. 2004. Ministério da Saúde. Agência Nacional de Vigilância Sanitária. Resolução: RDC n²16 de 15 de setembro de 2004. Dispõe sobre: Regulamento técnico de boas práticas para serviços de alimentação. Disponível em: <http:// www.anvisa.gov.br>. Acessado em: 11/2004.

6 Chen Y., Jackson K.M., Chea F.P. \& Schaffner D.W. 2001. Quantification and variability analysis of bacterial crosscontamination rates in common food service tasks. Journal of Food Protection. 64: 72-80.

7 Franco B.D.G.M. \& Landgraf M. 1996. Microbiologia de Alimentos. São Paulo: Atheneu, 181p.

8 Kaneko K.I., Hayashidani H., Takahashi T., Shiraki Y., Wongpranne S.L. \& Ogawa M. 1999. Bacterial contamination in the environmental of food factories processing ready-to-eat fresh vegetables. Journal of Food Protection. 62: 800-804.

9 Lukianocenko M. 2005. A evolução nos formatos continua. Superhiper. 357: 18-20.

10 Nascimento G.A., Barbosa J.S. 2007. BPF: Boas práticas de fabricação: uma revisão. Higiene Alimentar. 21: 24-30.

11 Parente J. 2000. Varejo no Brasil: gestão e estratégia. São Paulo: Atlas, 388p.

12 Reij M.W. \& Den Aantrekker E.D. 2004. Recontamination as a source of pathogens in processed foods. International Journal of Food Microbiology. 91: 1-11.

13 Rio Grande do Sul. 2001. Governo do Estado. Secretaria da administração e dos recursos humanos. Decreto $n^{\circ} 23430$ Regulamento sobre a promoção, proteção e recuperação da saúde pública. Porto Alegre: CORAG. 400p.

14 Scott E. \& Bloomfield S. 1990. The survival and transfer of microbial contamination via cloths, hands and utensils. Journal of Applied Bacteriology. 68: 271-278. 
Gottardi C.P.T.,M ottin V.D., Mürmann L., Saldanha C.A., Schmidt V. \& Cardoso M.Avaliação das práticas de fracionamento de produtos de origem animal em supermercad os em Porto Alegre. Acta Scientiae Veterinariae. 36(2): 167-172. 